\title{
Working for patients: will it work in practice?
}

\author{
Nigel R. Fisher, Senior Registrar; STUART R. TURNER, Senior Clinical Lecturer and \\ Honorary Consultant; and ROBERT PUGH, Consultant, Department of Psychiatry, \\ The Middlesex Hospital, Mortimer Street, London W1N 8AA
}

The College has described the White Paper, Working for Patients (Department of Health, 1989a), as "an artist's impression" (Royal College of Psychiatrists, 1989) with the lack of detail obscuring the full implications of the proposals. Some of this detail is now available in the form of a series of working papers. In fact these papers may raise more questions than they answer, and in some cases would seem to be inconsistent with pre-existing Government policy - especially that concerned with the care of the mentally ill in the community.

In one of only two specific references to mental illness, Working for Patients states that the service for mentally ill people is one of the " "core' services to which patients need guaranteed local access". However one of the principle innovations of the same paper is that District Health Authorities (DHAs), as purchasers of health services, should shop around, beyond their own boundaries, for the best value for money. Accounting systems are to be changed to facilitate "cross boundary flow" of funds, so encouraging DHAs to use services beyond their traditional catchment area and distant from the communities they serve. Thus DHAs may face the conflict between using a local service and getting a cheaper deal elsewhere. Severely disturbed or dangerous patients are likely to be the first victims in this dilemma. Already such patients are often managed in private facilities (paid for by DHAs) that are distant from the patients' local community. Little attention is paid to the importance of contact with that community, even though rehabilitation of the patient is the aim of such placements. In future, for these patients, detained under the Mental Health Act, with no choice as to whether or where they receive treatment, locality of a service would appear to matter little compared with cost.

In introducing the new financial initiatives, the White Paper identifies the problems inherent in the current RAWP based system of hospital funding. In particular it emphasises that there is "no direct relationship between the money a district is allocated and the number of patients its hospitals are treating". For the psychiatric services this is a particular problem for hospitals in areas that attract the mentally ill from beyond their resident population. Most frequently this is a result of geographical coincidence, for example being located near major transport termini or hostels for the homeless. Currently the needs of patients from these sources are rarely included in funding calculations.

The Government proposes that, "In future, [Districts] like Regions will be funded for their resident populations". Districts will then use this funding to buy services at the best price possible. The model for this system is that of day surgery (Peck, 1989) with the emphasis on one off interventions, high turnover and short waiting lists without the need to provide a continuing and flexible system of aftercare. It is, however, far from clear to what extent this model can be extended to psychiatric services where acute care is inseparable from continuing care, where hospital based care is being transferred to the community and where the emphasis is on services that are both proximal and accessible to the local population (Royal College of Psychiatrists, 1988). How does a DHA shop around for a community intervention service?

The problems that may arise in providing services for the local resident population are increased for that large group of psychiatric patients who drift from one area to another. The White Paper allows funds to follow patients across DHA boundaries; however the choice of which service to use lies not with the patient as user, but with the DHA as purchaser of those services. The new principle to be adopted is that wherever a patient presents to a service he will remain the financial responsibility of the DHA which covers his residence. Residential criteria, even for the homeless, are described in detail:

"The principle is that the patient's perception of where he
is resident (either currently or, failing that, most recently)
is the criterion. If patients consider themselves to be resi-
dent at an address, which is, for example, a hostel, there is
no reason why that should not be accepted. Equally a
DHA should continue to accept responsibility for a
patient if he considers himself not to have been resident
anywhere else since leaving its District." (Department of
Health, 1989b).

Considering the financial implications of residency it is surprising, and important, to note how subjective these criteria are.

It is instructive to examine how these criteria, together with the role of DHAs as purchasers of services, will work in some specific situations. For 
example, a patient resident in one DHA presents at a distant DHA. He is assessed, and found to be psychotic; indeed it is because of these psychotic phenomena that he drifted away from home. He is transferred to the service contractually purchased by his local DHA which both knows him well and can offer continuing care. Funding is to follow patients, so the distant DHA will be reimbursed for its initial assessment service. This is the system as it is intended to work.

Now consider the position of the patient who has left home, some months ago, not because of psychotic ideation, but for social necessity (e.g. domestic violence) or economic need (e.g. unemployment). Although he has expressed a clear wish not to return to his 'home' town, he has not established residency anywhere else. On assessment he is found to be psychotic and in need of treatment. The originating DHA is obliged to accept financial responsibility, but what services will it be prepared to purchase for this man? Rather than DHA funds following individual patients, the purchase of services in bulk will be the preferred option, patients then being directed to these services. In this case, it would be reasonable to assume that most of the DHA's budget has been appropriately used to provide a local psychiatric service. There may be a small contingency fund to cover the emergency out of district assessment, described in the first example. As a result, the financially responsible DHA may only be willing to sponsor treatment in its local service, but returning there is unacceptable to the patient for the reasons already given. The assessing, distant, service will only be able to offer treatment if the DHA of residence is prepared to pay for it. This it will resist because of the high rate the distant DHA is likely to charge for 'one-off' intensive services. The patient's 'choice' is between trying to live where he wishes and receiving the treatment he needs. This situation would be aggravated, and all patient choice removed, if the patient were to be detained under the Mental Health Act. In such cases the patient would almost certainly be obliged to receive treatment in his originating DHA. The moral and ethical problems of such a situation are obvious and have received all too little attention.

The new system does, however, offer some advantages for those hospitals that attract this drifting, often homeless population. These hospitals will now be able to charge for the patients they assess and treat, before their return to their 'local' service. This has the potential for being a source of income, in an area which until now has been a considerable financial burden. The number of patients involved is not small. In an audit of our unit $10 \%$ of acute inpatients would become the financial responsibility of another DHA if the White Paper residency criteria are applied (Fisher, Turner \& Pugh, 1990).
The subjectivity of the residency criteria will inevitably cause problems. In order to be treated where they want to be, patients may be pressured into giving the 'correct' answer. To some extent the phrasing of the White Paper criteria encourages this. If a hostel counts as a residence, will a cardboard box? The paper is correct in its implication that people should be free to choose where they live. However, by its liberal definition of residency there is a real risk that groups such as the homeless will continue to be excluded from the funding formulations for DHAs. This is because, by definition, they are not included in the Office of Population Censuses \& Surveys census data (which literally counts households) used to calculate the size of a DHA's resident population, the key determinant of funding. A similar difficulty arises with that group of patients who are quite unable to give either a past or a present place of residence, again, some $10 \%$ of in-patients in our unit (Fisher, Turner \& Pugh, 1990). A 'safety net' procedure will oblige DHAs to treat these patients, but without necessarily receiving revenue for this service. The financial burden of such patients could lead DHAs to contest their 'residency' status, or even coerce them into changing their minds. It is hard to imagine a hard-pressed DHA readily accepting an ongoing financial responsibility for a patient-say requiring long-term intensive care - because the patient was briefly in a hostel there some months ago, and considers this hostel to be his last place of residence.

A further area of dispute may be between local authorities and the DHAs. When the Care in the Community paper is eventually implemented local authorities will be purchasers of many long-term mental health services (Department of Health, 1989c). It remains unclear whether or not the same criteria that define DHA financial responsibility for patients will also apply to local authorities. Clearly if they do not, the resultant split between acute and continuing care will mean that many patients will fail to get the complete package of services they require. The group most likely to be neglected as a result of this division of financial responsibility is the homeless, of whom up to $40 \%$ are mentally ill (Tessler \& Dennis, 1989).

Residency and how it is defined will have a profound impact on the delivery of mental health services. For certain large and vulnerable groups of patients (e.g. the homeless) it is likely that DHAs will continue to be underfunded. However, this should not detract from the positive aspects of attempting to fund hospitals according to the uptake of their services. Interestingly, the same groups of patients, such as the homeless, fail to be included in financial calculations and also fail to gain access to clinical services. Administrators and clinicians alike have relied excessively on anecdotal reports on the nature and extent of, for example, 
mental health problems among the homeless (e.g. Weller, Tobiansky \& Hollander, 1989). This contrasts with the rigorous epidemiological studies carried out in America (Tessler \& Dennis, 1989). Commendably the White Paper makes it clear that DHAs will be expected to assess the needs of its local population. However such assessments, if they are to be of any value, are likely to be expensive and the funding of such exercises remains obscure.

The Government has initiated major changes in the way services within the NHS are provided. However, the same changes have been applied across all specialties and districts without taking into account the significant differences that exist between them. It is for clinicians to provide accurate data to describe these differences in order to justify claims to resources. It is only by doing so that the 'artist's impression' will gain sufficient detail to become a useful blueprint from which adequate and relevant services can be planned.

\section{References}

Department of Health (1989a) Working for Patients. London: HMSO.

- (1989b) Working Paper 11, Annex 12. London: HMSO.

(1989) Caring for People: Community Care in the Next Decade and Beyond. London: HMSO.

Fisher, N., Turner, S. \& PUGH, R. (1990) Homeless and mentally ill. Lancet, $i, 914-915$.

PECK, E. (1989) Working for psychiatric patients? Mental health services and the White Paper. Psychiatric Bulletin, $13,407-408$.

Royal College of Psychiatrists (1988) Caring for a Community. 1. The model mental health service. London: Royal College of Psychiatrists.

- (1989) Comments of the Royal College of Psychiatrists on the NHS White Paper: Working for Patients. Psychiatric Bulletin, 13, 385-389.

TESSLER, R. \& DENNIS, D. (1989) A Synthesis of NIMHfunded Research Concerning Persons who are Mentally Ill. Washington DC: National Institute of Mental Health.

Weller, M., Tobiansky, R. \& Hollander, D. (1989) Destitution at the festive season. Lancet, $i, 220$.

\title{
Choosing trust status: should we trust it?
}

\author{
D. H. Dick, Consultant Psychiatrist, Herrison Hospital, Dorchester, Dorset DT2 9RL
}

The proposals outlined in the White Paper, Caring for People, are now law and were little affected by the wave of protest which greeted them when they were first published. So the time has probably come to see what can be made of them and how they might be turned to advantage, rather than continuing to worry about the politics of whether change was necessary at all.

In the West Dorset Health District, especially within the psychiatric services based at Herrison Hospital, we decided early on that we should explore what opportunities might come from riding the wave of likely change rather than swimming against it. As the National Health Service is in a state of continuous change, there seemed little point in spending much energy in joining the automatic response which any proposal for change provokes. There might be advantages.

There were only five consultants in our adult mental health services so that we were able to come to a firmly shared decision quite quickly. We could begin the exploration of whether or not to choose trust status. It was clear that to retain the status quo would not be an option. We would either become a trust or a directly managed unit. The worst outcome of being directly managed would be to become a subdepartment of a large general hospital unit whose dominating priorities were those of acute medicine. The differences between trust and direct management would not be great. Those that there were would mean a lot to reaching the aims of the developments which we had nurtured for a long time. We wanted to regain control of the process of change in our services which has been steadily leaking away from clinicians, since the arrival of increasingly centralised management decisions, through the adoption of general management. We wanted to be able to set out our own priorities and not remain tangled in other parts of the health service which always seemed to attract more of the health authority's attention. 